\title{
Study of Bacterial Aetiogenicity of Pigment Gall Stones by Culture of Nidus of Calculus and correlation between Stone Culture and Bile Culture
}

\author{
Mahmood Rashid Shiekh', Tahleel Shera ${ }^{2}$, Shiekh Aamir Rashid ${ }^{3}$, Altaf Hussain Shera ${ }^{4}$, \\ Junaid Ahmad \\ 1,4 Department of General Surgery, Govt. Medical College, Baramulla \\ 2 Department of Radio Diagnosis, Govt. Medical College, Baramulla \\ ${ }^{3}$ ASCOMS, Jammu \\ ${ }^{5}$ Department of Microbiology, Govt. Medical College, Baramulla
}

\section{A B S T R A C T}

\begin{abstract}
Background: Calculus disease of biliary tract is a major public health problem in north Kashmir and pigment gall stones form a significant portion of gall stones in our region. In this study we prospectively studied 84 cases of pigment gall stones to examine the role of bacteria in the formation of these stones.

Objective: To study the bacterial aetiology of pigment gall stones.

Methods: A hospital based prospective study of 84 consecutive cases of pigment gall stones was done from December 2012 to November 2019 and the results of stone culture and bile culture were statistically analysed. Informed consent was obtained from all the patients in the study group.

Results: A total of 84 cases studied included $32(38.09 \%)$ male patients and $52(61.91 \%)$ female patients. The median age was 48.5 years and mean age was 46.2 years. Of 84 patients, $21(25.00 \%)$ had black pigment stones and $63(75.00 \%)$ had brown pigment stones. $61(72.62 \%)$ patients presented with biliary colic and $24(28.57 \%)$ patients had chronic cholecystitis. Bile culture was positive in $46(54.76 \%)$ patients and stone culture was positive in $70(83.33 \%)$ patients.

Conclusion: A strong association was observed between stone culture and bile culture results (showing similar beta-glucronidase producing bacteria) and pigment stone formation.

Key words: Gall stones, stone culture, bile culture, nidus

JMS: 2020; 23(3):8-12 DOI: https://doi.org/10.33883/jms.v23i3.746
\end{abstract}

\section{INTRODUCTION}

Gall stone disease is known to mankind since ancient times. ${ }^{1}$ Pigment gall stones have been referred to as early as $500 \mathrm{AD}$ by Alexander of Tralle ${ }^{2}$. These constitute $10 \%$ to $27 \%$ of all types of gall stones found in general population and both intrahepatic gall stones and stones caused by bile stasis or cirrhosis are usually pigment stones ${ }^{3}$. Pigment stones are usually multiple, 2 to $5 \mathrm{~mm}$ in diameter, irregular to smooth in shape, black to brown in colour and amorphous or crystalline on cross section. Pigment stones, especially the brown ones, can form within extra hepatic and intra hepatic ducts apart from their usual occurrence in the gall bladder

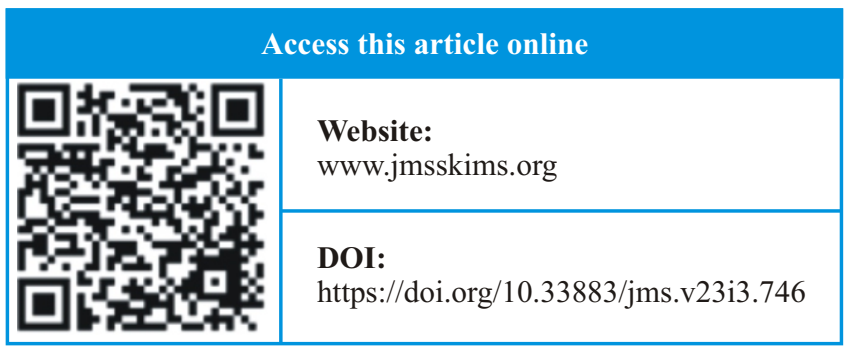

and are commonly associated with ascending cholangitis. Enteric bacteria have been found to play a significant role in pigment gall stone formation and these stones in general and brown ones in particular have a tendency to recur while black gall stone disease is usually non recurrent ${ }^{4}$. Unlike the causative factors like cirrhosis, ileal resection etc. observed in the West, infection has been found to be a predominant cause in South East Asia. ${ }^{10}$ In this study, we prospectively
Correspondence:
Dr. Shiekh Mahmood Rashid
Assistant Professor, General Surgery,
Govt. Medical College, Baramulla
Email:mahmoodshiekh234@gmail.com

How to cite this article: Anand S, Ahmed O, Kundal V. Clinical spectrum and out comes of snake bite patients admitted in a tertiary care hospital , A prospective observational hospital based study.JMS 2020;23(3):8-12

Received: 2020-05-09 Accepted: 2020-08-11 
Shiekh MR et al., Study of Bacterial Aetiogenicity of Pigment Gall Stones by Culture of Nidus of Calculus

studied 84 patients with pigment gall stones disease to examine the role of beta glucronidase producing bacteria in the formation of these type of stones. 'Pigment gall stones' included any black or dark brown stone containing less than $25 \%$ cholesterol, whether or not pigment was its major component and irrespective of the nature and proportion of other constituents ${ }^{13}$.

\section{MATERIALAND METHODS}

A hospital based prospective study was carried out from December 2012 to November 2019 in the departments of General Surgery, Microbiology and Radio diagnosis of Govt. Medical College Baramulla, Kashmir. It included a total of 84 consecutive patients with pigment gall stones (confirmed by chemical analysis of extracted gall stones). A formal informed consent was taken from all of them. The patients were selected as they fulfilled the following inclusion criteria: confirmed to have pigment gall stones, that is, black to dark brown gall stones containing less than $25 \%$ cholesterol irrespective of the proportion of other constituents and whether are not pigment was its major constituent $^{20}$; not on any medication for gall stones for last three months and had not received antibiotics for two weeks prior to surgery.

A detailed account of history was taken and complete physical examination was performed. Routine investigations including complete blood count, liver function tests, serum amylase and calcium levels were requested as also an abdominal ultrasound performed to know about the location, number and size of gall stones and gall bladder wall thickness or oedema and any associated dilatation of hepato-pancreatic ducts was ruled out. In selected cases, an abdominal computerised axial tomogram or a magnetic resonance cholangiogram was also done to exclude or to elaborate on any added pathology.

All the 84 patients were subjected to cholecystectomy and gall bladder sample along with the stones within it was placed aseptically in a container. 5 to $10 \mathrm{ml}$ of bile was aspirated from within the gall bladder and preserved for bile culture and sensitivity in all the 84 cases during the operative procedure. The gall stones were removed and immediately transferred to a McCartney bottle containing $5 \mathrm{ml}$ of normal saline for further processing. A portion of stone was sent for chemical analysis and the other portion preserved for microbiological evaluation. Only those calculi were included in the present study whose chemical analysis results fulfilled the criteria already stated for the case of pigment stones.

A technique for culture of calculi as devised by Nemoy and Stamey $^{22}$ in 1971 was done. The culture methods were designed for localization of bacteria to the substance of the calculus and to distinguish bacteria within a stone from surface colonization. Under all aseptic precautions, a portion of stone was washed consecutively in four test tubes containing $5 \mathrm{ml}$ of sterile saline each and then crushed in another tube in a laminar air flow chamber. $0.1 \mathrm{ml}$ of fluid from washes 1 and 4 and of the fluid of crushed stones were quantitatively cultured in Blood Agar, McConkay Agar and Brain Heart Infusion Broth and Agar. The cultures were studied at 24 hours and 48 hours and organisms typed. An increased density of isolate in the fluid of crushed stone and increased colony count after culture compared with the fluid of wash 4 was considered evidence for bacteria within a stone. The spectrum of bacteria that colonized the pigment stone was detailed out to assess their relation with the genesis of pigment gall stones.

\section{RESULTS}

In the present study of 84 consecutive patients with pigment gall stones, confirmed by stone analysis, conducted in the department of General Surgery at Govt. Medical College Baramulla, 32(38.09\%) patients were males and $52(61.91 \%)$ patients were females. The median age was 48.5 years and mean age was 46.2 years. The distribution of study subjects as per the type of stones found in 84 patients showed that $21(25.00 \%)$ patients had black pigment stones and $63(75.00 \%)$ patients had brown pigment gall stones. (Table 1).

Table 1: Distribution of 84 study subjects as per type of stone.

\begin{tabular}{|l|c|c|}
\hline Type of pigment stone & Number & Percentage (\%) \\
\hline Black pigment stones & 21 & 25.00 \\
\hline Brown pigment stones & 63 & 75.00 \\
\hline Total & 84 & 100 \\
\hline
\end{tabular}

Of 84 study subjects, $61(72.62 \%)$ patients presented with biliary colic, and $24(28.57 \%)$ patients presented with chronic cholecystitis. Acute infective conditions like acute cholecystitis were observed in $2(2.38 \%)$ patients. $16(19.05 \%)$ patients presented with ultrasonic evidence of mucocele or empyema of gall bladder prior to surgery. Only $1(1.19 \%)$ patient had a documented predisposing cause in 
Shiekh MR et al., Study of Bacterial Aetiogenicity of Pigment Gall Stones by Culture of Nidus of Calculus

the form of glucose 6 phosphate deficiency haemolytic anaemia. (Table 2).

Table 2: Distribution of cases as per the presenting features

\begin{tabular}{|l|c|c|}
\hline Presenting feature & Number & Percentage (\%) \\
\hline Biliary colic & 61 & 72.62 \\
\hline Chronic cholecystitis & 24 & 28.57 \\
\hline Acute cholecystitis & 02 & 2.38 \\
\hline USG evidence of infection & 16 & 19.05 \\
\hline $\begin{array}{l}\text { Predisposing causes in the } \\
\text { form of G6PD deficiency } \\
\text { haemolytic anaemia }\end{array}$ & 01 & 1.19 \\
\hline
\end{tabular}

Intra operative findings revealed thickened gallbladder wall suggesting chronic cholecystitis in $46(54.76 \%)$ patients; $3(3.57 \%)$ patients had dense adhesions of gallbladder with surrounding viscera and $3(3.57 \%)$ patients had gall bladder perforation with cholecystoenteric fistula formation. (Table $3)$.

Table 3: Presentation of subjects at the time of surgery.

\begin{tabular}{|l|c|c|}
\hline \multicolumn{1}{|c|}{ Intraoperative presentation } & Number & Percentage (\%) \\
\hline Thickened gallbladder wall & 46 & 54.76 \\
\hline Gallbladder perforation & 03 & 3.57 \\
\hline Adhesions & 03 & 3.57 \\
\hline
\end{tabular}

Of 84 study subjects, bile culture was positive in 46 $(54.76 \%)$ cases while stone culture was positive in 70 $(83.33 \%)$ cases. Both bile and stone cultures were positive in $32(38.09 \%)$ cases; bile culture was negative but stone culture was positive in $38(45.24 \%$ ) cases while in 14 (16.67\%) cases both the cultures were negative.(Table 4). The stones which were positive showed uniform distribution of bacteria throughout the stone including its core as confirmed by the culture and sensitivity reports of the fragments of the stone including its core.

Table 4: Comparison of stone culture and bile culture results of 84 study subjects

\begin{tabular}{|l|c|c|}
\hline \multicolumn{1}{|c|}{ Culture positivity } & Number & Percentage (\%) \\
\hline Bile culture positive & 46 & 54.76 \\
\hline Stone culture positive and bile culture positive & 32 & 38.09 \\
\hline Stone culture positive and bile culture negative & 38 & 45.24 \\
\hline Stone culture negative & 14 & 16.67 \\
\hline Bile culture negative & 38 & 45.24 \\
\hline
\end{tabular}

Of $70(83.33 \%)$ culture positive stone culture results, $11(13.09 \%)$ black stones and $59(70.24 \%)$ brown stones were culture positive for bacteria (Table 5).

Table 5: Stone culture results of 84 study subjects.

\begin{tabular}{|l|c|c|}
\hline Evidence of bacteria & Number & Percentage (\%) \\
\hline Stone culture positive & 70 & 83.33 \\
\hline Stone culture negative & 14 & 16.67 \\
\hline Presence of bacteria in black stones & 11 & 13.09 \\
\hline Presence of bacteria in brown stones & 59 & 70.24 \\
\hline
\end{tabular}

Most of the bacteria were bacillary forms and E. coli was the commonest organism grown in $73.81 \%$ of stone cultures. Few cultures revealed other types of bacteria such as Klebseilla (3.57\%), Salmonella typhi (3.57\%) and Staphylococcus aureus. (Table 6). In some of the samples, there were groups of bacteria suggesting colony formation.

Table 6: Distribution of 70 patients with culture positive stone nuclei in relation to bile culture results.

\begin{tabular}{|l|cc|cc|}
\hline Bacteria & \multicolumn{2}{|l|}{$\begin{array}{l}\text { Number of patients with } \\
\text { culture positive stone } \\
\text { cultures } \\
\text { Number }\end{array}$} & \multicolumn{2}{l|}{$\begin{array}{l}\text { Bile culture showing same } \\
\text { bacteria }\end{array}$} \\
ercentage (\%) & Number & Percentage (\%) \\
\hline E.coli & 62 & 73.8 & 28 & 33.33 \\
\hline Klebseilla & 3 & 3.57 & 1 & 1.19 \\
\hline Salmonella Typhi & 3 & 3.57 & 2 & 2.38 \\
\hline Staphylococcus aurues & 2 & 2.38 & 1 & 1.19 \\
\hline Total & 70 & 83.33 & 32 & 38.09 \\
\hline
\end{tabular}

\section{DISCUSSION}

In the present study, out of 84 patients studied, 32(38.09\%) patients were males and $52(61.91 \%)$ patients were females. The median age was 48.5 years and mean age was 46.2 years. Of 84 patients studied, 21(25.00\%) patients had black pigment stones and 63( $75.00 \%)$ patients had brown pigment stones. $72.62 \%$ patients presented with biliary colic and $28.57 \%$ patients presented with chronic cholecystitis. At surgery $54.76 \%$ patients had thickened gallbladder wall suggesting chronic inflammation and 3.57 $\%$ cases presented with gallbladder perforation. These findings correlated with those of Akiyoshi $\mathrm{T}$ and Nakayama $\mathrm{F}^{20}$. The central portions (nidus) of the stones collected from 84 patients were cultured as per the technique already described. It was observed that $83.33 \%$ of the stones from 70 patients were culture positive and $16.67 \%$ of the stones from 14 patients were cultured negative. Of $83.33 \%$ culture positive patients, beta glucronidase producing organisms were found in $73.81 \%$ of patients. Of 70 culture positive stone cases, $32(38.09 \%)$ had bactobilia with same organisms. These findings suggest that bacterial infection with beta glucronidase producing organisms plays a significant role in pigment gallstone formation and pigment gall stones are the tomb stones of bacteria; in addition it was observed that majority of black pigment stones were not associated with predisposing causes such as ileal resection, cirrhosis of liver or haemolytic disease unlike the observations in Western studies ${ }^{21}$ and were again found to be associated with infection of stone nuclei and bile. Authors 
Shiekh MR et al., Study of Bacterial Aetiogenicity of Pigment Gall Stones by Culture of Nidus of Calculus

wanted to explore at this aspect and especially to explore the association of black pigment stones with bacterial infection of bile and stone material. It was found that a significant portion $(25.00 \%)$ of our study subjects who had black pigment stones had no predisposing factors mentioned above in Western world and were again fund to be associated with recurrent biliary infection.

Though it was observed that bacteria are possibly etiological agents due to the evidence at hand, we cannot exclude the possibility that they are innocent by standers. The fact that bacteria were found in the nuclei of multilayered stones favours the hypothesis that bacteria are associated with stones at a nascent stage of their development. These findings are supported by the work of Soloway $\mathrm{RD}$ et $\mathrm{al}^{24,25}$. The possible mechanism in pigment stone formation could be a combination of cholecystitis and bile duct occlusion due to bacterial infection producing excessive mucous formation and release of deconjugated bilirubin, bile acids, hydrolyzing phospholipids and calcium, there by leading to pigment stone formation ${ }^{5-9,11,12}$. Similar observations have substantiated the close association of bacteria with brown pigment stone formation $^{15-19,14,23}$.

\section{CONCLUSION}

Considering all these findings, it could be suggested that hepatobiliary tract infection with beta glucronidase producing bacteria has a significant role in the formation of pigment gall stones. Bacteriological study of a large number of stones especially in relation to their age, chemical composition and serial culture of patients might help in further establishing the role of bacterial infection in stone formation.

Financial support and sponsorship: Nil

Conflict of Interest: There are no conflict of interest

\section{REFERENCES}

1. Berci G. Historical overview of surgical treatment of biliary stone disease. In:MacFadyen BV, Arregui M,Eubanks S,Olsen DO,Peters JH,Soper NJ, et al,. Laparoscopic Surgery of the Abdomen. New York: Springer; 2004: 139-142.

2. Alexander of Tralle, cited by Rains AJH: Gall stones: Causes and Treatment. Springfield, III, Charles C Thomas, 1964, p.1.
3. Baig SJ, Biswas S, Das S, Basn K, Chatopaddyay G. Histopathological changes in gall bladder mucosa in cholelithiasis: Correlation with chemical composition of gall stones. Trop Gastro enteral. 2002; 23: 25-27.

4. Branganza JM, Worthington H.A. Radical view of gall stone aetiogenesis. Med Hypotheses. 1995; 45: 510516.

5. Shiesh SC, Chen CY, Lin XZ, Lin ZA. Melatonin prevents pigment gall stone formation induced by bile duct ligation in guinea pigs. Hepatology. 2000; 32: 455-460.

6. Lin XT, Hu J. Relationship between bilirubin free radical and formation of pigment gall stones. World $\mathrm{J}$ Gastro enteral. 2002;8:413-417.

7. Haigh WG, Lee SP. Identification of oxysterols in human bile and pigment gall stones. Gastroenterolgy 2001; 121:118-123.

8. Leonard MR, Andrade JD. Striking alterations in bilirubin and bile salt solution chemistry of gall bladder bile in a germ free mouse model of black pigment gall stones. Gastroenterology. 2011; 140 suppl 1:568.

9. Whary MT, Woods SE, Fox JG. Pigment gall stones in germ free Swiss Webster mice. Gastroenterology. 2010; 138 suppl 1:S 211.

10. Fan Y, Wu SD, Sun L. Possible relationship between intestinal barrier function and formation of pigment gall stones in hamsters. Hepatobiliary Pancreat Dis Int. 2008;7: 529-532.

11. Rahman GA. Cholelithiasis and Cholecystitis: changing prevalence in an African community. J Natl MedAssoc. 2005; 97:1531-1538.

12. Ostrow JD. Unconjugated bilirubin and cholesterol gall stone formation. Hepatology. 1990; 12: 219S$226 \mathrm{~S}$.

13. Donavan JM, Carey MC. Physicochemical basis of gall stone formation. Gastroenterol Clin North Am. 1991; 20:47-66.

14. Ostrow JD, Mukerjee P. Revalidation and rational for high Pka values of unconjugated bilirubin. BMC Biochem. 2007; 8:7.

15. Vang L, Shen W, Wen J. An animal model of black 
Shiekh MR et al., Study of Bacterial Aetiogenicity of Pigment Gall Stones by Culture of Nidus of Calculus

pigment gall stones caused by nanobacteria. Dig Dis Sci. 2006; 51:1126-1132.

16. Vitak L, Carey MC. Enterohepatic cycling of bilirubin as a cause of black pigment gall stones in adult life. Eur J Clin Invest. 2003; 33: 799-810.

17. Aydogdu I, Sari R, Ulu R, Sevince A. The frequency of gall bladder stones in patients with perinicious anaemia. J Surg Res. 2001; 101: 120-123.

18. Diehl AK, Holleman DR. Clinical correlates of gall stone composition: distinguishing pigment from cholesterol stones. Am J Gastro enteral. 1995; 90: 967972.

19. Hoffman AF, Ton Nu HT, Mysels KJ. Solubility of calcium salts of unconjugated and conjugated natural bile acids. J Lipid Resp. 1992;33:635-646.

20. Akiyoshi T, Nakayama F. Bile acid composition in brown pigment stones. Dig Dis Sci. 1990;35:27-32.

21. Kaufman HS, Magnuson TH, Lillemoe KD. The role of bacteria in gall bladder and common duct stone formation. Ann. Surg. 1989; 209: 584-591.

22. Nemoy NJ. Surgical, bacteriological and biochemical management of infection stones. JAMA.1971;215: 1470-76.

23. Stewart L, Oesterle AL, Erdan I, Griffiss JM, Way LW. Pathogenesis of pigment gall stones in Western socities; the central role of bacteria. J Gastrointest Surg. 2002; 6(6): 891-930.

24. Soloway RD, Trotman BW, Ostrow JD, Pigment versus Cholesterol cholelithiasis: comparison of stone and bile composition. Am J Dig Dis. 1974; 19:585-90.

25. Trotman BW, Soloway RD. Pigment versus Cholesterol cholelithiasis; clinical and epidemiological aspects. Am J Dig Dis. 1975;20:73540. 